\title{
Early Administration of Surfactant in Preterm Newborns with Respiratory Distress Syndrome
}

\author{
Ngo Minh Xuan* \\ Pham Ngoc Thach University of Medicine, Ho Chi Minh city, Vietnam \\ *Corresponding author: Ngo Minh Xuan, Pham Ngoc Thach Medical University, Duong Quang Trung street, District 10, \\ Ho Chi Minh City, Vietnam
}

ARTICLE INFO

Received: March 13, 2020

Published: 幽 April 17, 2020

Citation: Ngo Minh Xuan. Early Administration of Surfactant in Preterm Newborns with Respiratory Distress Syndrome. Biomed J Sci \& Tech Res 27(1)-2020. BJSTR. MS.ID.004450.

Abbreviations: NICUS: Neonatal Intensive Care Units, RDS: Respiratory Distress Syndrome, MV: Mechanical Ventilation, ETI: Endotracheal Intubation, AAP: American Academy of Pediatrics, CPAP: Continuous Positive Airway Pressure, GA: Gestational Age, BPD: Bronchopulmonary Dysplasia, DR: Delivery Room, NEC: Necrotizing Enterocolitis, IVH: Intraventricular Hemorrhage

\author{
ABSTRACT
}

Background: Current guidelines for management of Respiratory Distress Syndrome (RDS) recommend Continuous Positive Airway Pressure (CPAP) as the primary mode of respiratory support even in the most premature neonates, reserving Endotracheal Intubation (ETI) for rescue surfactant or respiratory failure. The incidence and timing of ETI in practice is poorly documented.

Methods: In NICU of Tu Du Hospital (Ho Chi Minh city, Vietnam), demographics and baseline characteristics, respiratory support modalities including timing of ETI, administration of surfactant and caffeine/other methylxanthines, and neonatal morbidities were prospectively recorded in consecutive preterm neonates following written parental consent. Infants were divided into two groups according to Gestational Age (GA) at birth, namely 28-30 and 30-32 weeks. Statistical comparisons between groups were done using Chi-Square tests.

Results: Of 112 neonates, 53 (47.3\%) were 28-30 weeks GA, 59 (53.7\%) were 30-32 weeks. Antenatal steroid use was $14.3 \%$. CPAP was initiated in all infants. The successful treatment rate is $72.3 \%$; failure is $27.7 \%$. The percentage of pediatric patients who do not have to be intubated at 72 hours is $44.6 \%$.

Conclusion: Despite published guidelines for management of RDS, rate and timing of ETI varies widely, apparently unrelated to severity of illness. The impact of this variability on outcome is unknown but provides opportunities for further approaches which can avoid the need for ETI.

Keywords: Preterm Infants; Respiratory Distress Syndrome; Surfactant

\section{Introduction}

The respiratory management of preterm infants with or at risk for Respiratory Distress Syndrome (RDS) has evolved dramatically in Neonatal Intensive Care Units (NICUs) over the past decade. Results from several randomized trials have suggested that early use of Continuous Positive Airway Pressure (CPAP) offers potential benefits over Endotracheal Intubation (ETI) and Mechanical Ventilation (MV) with or without administration of surfactant for preterm infants [1-3]. This has led to practice guidelines and recommendations by the American Academy of Pediatrics (AAP) and other agencies to utilize CPAP as the primary mode of respiratory support even in the most premature neonates [4,5]. A recent metaanalysis suggested that avoiding ETI and MV significantly reduces the incidence of death or Bronchopulmonary Dysplasia (BPD) in premature infants less than 30 weeks Gestational Age (GA) [6]. Furthermore, the procedure of ETI can result in complications, and primary intubation as well as reintubation have been recognized as risk factors for death and other morbidities in preterm infants [79]. Despite the AAP guidelines recommending CPAP as the primary mode of respiratory support even in the most premature neonates, frequently, preterm infants are intubated in the Delivery Room (DR) for resuscitative maneuvers and delivery of surfactant [10].

Moreover, of those who get initiated on CPAP, a variable proportion fail this therapy and ultimately are intubated. Dargaville and colleagues recently reported on a large cohort of over 19 
thousand inborn infants admitted to NICU's from the Australia and New Zealand Neonatal Network between 2007 and 2013 [11]. Infants who did not need respiratory support in the first $24 \mathrm{~h}$ after birth or those who had rupture of membranes for $>14$ days (approximately 14\% of the original cohort) were excluded. About $70 \%$ of infants between 25 and 28 completed weeks and $21 \%$ of those between 29 and 32 weeks were intubated before CPAP was initiated. Among those managed initially on CPAP, 43 and $21 \%$ of those GA groups experienced CPAP failure, respectively. Infants who failed CPAP were at higher risk for death and other adverse outcomes. The timing of CPAP failure and reasons were not described in detail. Many single center reports published prior to the Dargaville report had suggested that the most common cause of CPAP failure among preterm infants is surfactant deficiency, probably because avoiding ETI delays the usual approach to surfactant replacement therapy [12,13]. More recently, alternative "less invasive" or "minimally invasive" approaches for surfactant administration have been advocated such as "LISA" or "MIST", however these are not widely used in all regions [14,15].

Given these changes in approaches to respiratory management, it still remains unclear what proportion of preterm infants at a given GA need ETI and surfactant replacement therapy, as well as the timing and reasons for these therapeutic interventions. Thus, our objective was to prospectively identify, describe, and compare in a broad, non-selective and contemporary cohort of preterm neonates their initial respiratory management, with particular emphasis on the incidence, indications, timing and conditions resulting in ETI and surfactant administration. We sought to characterize these events in all preterm infants, without exclusions, admitted to NICU's across several geographical areas.

\section{Materials and Methods}

This prospective observational study was reviewed and approved by Tu Du hospital research ethics boards. After obtaining written informed parental/legal representative consent, we prospectively recorded pertinent data in all consecutive preterm neonates between 28 and 32 weeks GA admitted to Neonatal Intensive Care Unit of Tu Du Hospital (Ho Chi Minh city, Vietnam). Gestational age assignment was based on last menstrual period or on Ballard assessment postnatally. All data collected were de-identified to ensure compliance with patient privacy rights. The information recorded included demographic and baseline characteristics, as well as pregnancy-related history including administration of antenatal steroids. In addition, we collected more detailed clinical data primarily focused on the initial use of respiratory support modalities including utilization of CPAP, timing and reasons for ETI, administration of surfactant and caffeine/ other methylxanthines, and occurrence of neonatal morbidities during the first 7 days after birth. Investigators could designate more than one reason for ETI. Notably, surfactant administration was not offered as a reason for intubation in an attempt to identify and capture the clinical factors prompting the need for surfactant.
The definitions of common neonatal morbidities used were as follows: RDS, presence of clinical signs of respiratory distress and need for supplemental oxygen with chest X-Ray confirmation; Patent Ductus Arteriosus (PDA), clinical signs and echocardiographic confirmation; Intraventricular Hemorrhage (IVH), seen on cranial ultrasound and graded as described by Papile et al. [16] and Necrotizing Enterocolitis (NEC), presence of clinical and radiographic signs as described by Bell et al. [17]. Statistical comparison between groups were done using Chi-Square tests

\section{Results}

From January 2013 to July 2014 a total of 112 preterm neonates were enrolled and provided evaluable information. Of these, 53 (47.3\%) were 28-30 weeks GA, 59 (53.7\%) were 30-32 weeks. Other characteristics of this cohort are listed in Table 1. Antenatal steroid exposure was inversely related to gestational age; $81 \%$ of all infants and $89 \%$ of neonates $\leq 32$ weeks were exposed to antenatal steroids. The use of antenatal steroids, incidence of RDS, and the utilization of ventilatory support or supplemental oxygen were similar across all countries. The successful treatment rate is $72.3 \%$; failure is $27.7 \%$. The percentage of pediatric patients who do not have to be intubated at 72 hours is $44.6 \%$. Overall mortality during the first 7 days after birth was low (Tables $1 \& 2$ ). Also, air leaks were observed infrequently, and the majority were pneumothoraces (data not shown). As expected, the rate of common morbidities associated with prematurity observed during the first 7 days was higher at lower GA. No data were collected beyond 7 days of life given the study objectives of capturing data during the first 7 days of life; therefore, the incidence of complications of prematurity is undoubtedly underestimated since the entire neonatal period has not been considered.

Table 1: Demographic characteristics.

\begin{tabular}{|c|c|}
\hline Demographic Characteristics & All Patients (n=112) \\
\hline Gestational age, mean (SD) & $30.2(1.2)$ \\
\hline Male, n (\%) & $59(52.6 \%)$ \\
\hline Cesarean delivery, n (\%) & $68(60.7 \%)$ \\
\hline Antenatal Steroids, n (\%) & $16(14.3 \%)$ \\
\hline APGAR at 5 minute (median) & 7 (range: $4-9)$ \\
\hline Singleton, n (\%) & $81(72.3)$ \\
\hline
\end{tabular}

Table 2: Mortality and common neonatal morbidities during the first 7 days

\begin{tabular}{|c|c|}
\hline C & All Patients (n=112) \\
\hline Death & $4(4.5 \%)$ \\
\hline Air leaks & $2(1.8 \%)$ \\
\hline Ventilator-associated pneumonia & $22(19.6 \%)$ \\
\hline Pulmonary hemorrhage & $4(3.6 \%)$ \\
\hline
\end{tabular}

\section{Discussion}

Presently, the respiratory management of preterm infants with or at risk for respiratory problems frequently involves the use of 
CPAP as the first line of therapy. This has been recommended for even the most premature neonates $[4,5]$. Whereas this approach may lower the risk of death and BPD, it remains unclear what proportion amongst all preterm infants born at a certain GA are actually able to be managed successfully only with CPAP, especially at lower gestational ages. Large randomized trials comparing CPAP to other approaches (e.g. ETI and surfactant administration) have focused on more selected populations because of their eligibility criteria, which usually involved more stable preterm infants not in need of resuscitation [1-10]. This hinders the generalizability of those findings to all or most preterm infants of similar gestational ages. Thus, it becomes quite important to have good estimations of what the initial respiratory management entails for all infants at a given gestational age. A recent report by Chawla and colleagues [18] using data from the SUPPORT trial conducted by the Neonatal Network of NICHD revealed that $81 \%$ of infants enrolled between 24 and 28 weeks GA were intubated during the first $24 \mathrm{~h}$ after birth. Also, recently published data including infants $<28$ weeks cared for in Canadian NICU's showed that at least $74 \%$ were intubated to receive surfactant [10].

It is even possible that additional infants were intubated and then extubated without receiving surfactant. Within the Australia and New Zealand Neonatal Network, 70\% of infants between 25 and 28 weeks GA and $21 \%$ of those $29-32$ weeks GA were intubated [11]. Data from these reports and our own contemporary study are remarkably consistent in these findings and reveal that ETI is used frequently among preterm infants, despite recent recommendations and relatively high exposure to antenatal steroids. Our data also show that across the regions involved in our study the proportion of preterm infants that were intubated was remarkably similar. However, within each region there was substantial variability among centers. Such variability is not uncommon in clinical practice, especially over time, and has been previously shown for specific interventions and outcomes [11,19,20]. This notwithstanding, the overall frequency of ETI reported by most centers in our study is within what has been published in several other studies $[2,10,11,18,19]$.

The method used for administration of surfactant is evolving to less invasive approaches $[14,15,21]$. These techniques seek to avoid classic ETI using an endotracheal tube and MV. Albeit brief and using a different device (catheter as opposed to an ETT), this approach still requires intubation of the trachea. Many of the controlled trials of these new approaches have not been large in size and have reported variable improvements in clinical outcomes $[3,14,22,23]$. A recent systematic review utilizing network metaanalysis suggested that "Less Invasive Surfactant Administration" (LISA), a procedure in which surfactant is administered into the lower airway after cannulation using a smaller flexible tube (like a nasogastric tube), results in less death or BPD than using other techniques [24] This notwithstanding, LISA was infrequently used among the 27 NICU's that participated in our study and the preferred method of surfactant administration reported involved ETI. This technique requires appropriate skill and experience to visualize and insert a small catheter through the vocal cords $[10,15]$.

The GA category in which CPAP was started more frequently was between 29 to $32+6$ weeks. The low proportion of infants that underwent a CPAP trial in the DR (i.e. first $15 \mathrm{~min}$ of life) reflects the need of intubation and resuscitation maneuvers in the sicker infants (high incidence of RDS regardless of GA) or a lack of willingness to provide a trial of CPAP. Dargaville and colleagues reported starting CPAP on a higher proportion of these infants, but they only reported on infants who developed respiratory distress, whereas our study included all infants [11]. This notwithstanding, as demonstrated in our findings and other reports, CPAP failure is relatively common among preterm infants, especially at lower gestational ages [11,12]. We did not characterize the pressures used while on CPAP or which type of CPAP was utilized. Rather, we focused on why infants underwent ETI, which included those who were started on CPAP. Recently, an additional report by Dargaville and colleagues suggested that selective use of minimally invasive surfactant administration improves the success of CPAP among infants 29-32 weeks GA [15]. These methods are, as noted above, not without risk since visualization of the vocal cords and use of a laryngoscope are still required. Having alternative ways to administer surfactant without ETI should increase the likelihood of avoiding MV and potentially decreasing other morbidities. Recent, albeit few and relatively small studies, have focused on administration of surfactant without invading the lower airway, namely using a laryngeal mask airway, and, via aerosolization [25-27]. If these approaches are shown to be successful, it would provide additional tools with which to improve the respiratory management of preterm infants.

Since the publication by Schmidt and colleagues of a potentially beneficial effect of caffeine on lowering BPD among preterm infants $<1250 \mathrm{~g}$ at birth, its use has dramatically increased [28,29]. In that trial, caffeine was started at a median age of 3 days. A more recent smaller trial reported improved hemodynamics and a strong trend towards lower need for intubation by administration of caffeine within $2 \mathrm{~h}$ after birth [30,31]. This preliminary finding was not substantiated by a large, observational trial by Patel et al., which did not find that early caffeine administration on the day of birth decreased the rate of CPAP failure in very low birth weight infants [29]. It should be noted that LISA and related techniques are most commonly performed after the infant has received caffeine, often within the first 30-60min of life. Our data clearly show that caffeine/other methylxanthines are used widely and started early; however, our study did not evaluate the timing of caffeine treatment relative to ETI. This observational study, collected data in prospective manner from all neonates admitted to the NICU who met entry criteria and for whom informed consent was obtained. Participating centers employed. 


\section{References}

1. Morley CJ, Davis PG, Doyle LW (2008) Nasal CPAP or intubation at birth for very preterm infants. New Engl J Med 358: 700-708.

2. Finer NN, Carlo WA, Walsh MC, Rich W, Gantz MG, et al. (2010) Early CPAP versus surfactant in extremely preterm infants. N Engl J Med 362(21): 1970-1979.

3. Dunn MS, Kaempf J, De Klerk A, De Klerk R, Reilly M, et al. Randomized trial comparing 3 approaches to the initial respiratory Management of Preterm Neonates. Pediatrics 128(5): e1069-e1076.

4. (2014) Committee on Fetus and Newborn, American Academy of Pediatrics. Respiratory support in preterm infants at birth. Pediatrics 133(1): 171-174

5. Sweet DG, Carnielli V, Greisen G (2013) European Association of Perinatal Medicine. European consensus guidelines on the management of neonatal respiratory distress syndrome in preterm infants-2013 update. Neonatology 103(4): 353-368.

6. Subramaniam P, Ho JJ, Davis PG (2016) Prophylactic nasal continuous positive airway pressure for preventing morbidity and mortality in very preterm infants. Cochrane Database of Systematic Reviews 6: CD001243.

7. Hatch LD, Grubb PH, Lea AS, Walsh WF, Markham MH, et al. (2016) Endotracheal intubation in neonates: a prospective study of adverse safety events in 162 infants. J Pediatr 168: 62-66.

8. Fischer HS, Buhrer C (2013) Avoiding endotracheal ventilation to prevent bronchopulmonary dysplasia: a meta-analysis. Pediatrics 132: e1351-e1360.

9. Guardia CG, Moya FR, Sinha S (2011) Reintubation and risk of morbidity and mortality in preterm infants after surfactant replacement therapy. J Neonatal Perinat Med 4:101-109.

10. Stritzke A, Mohammad K, Shah P (2018) Use and timing of surfactant administration: impact on neonatal outcomes in extremely low gestational age infants born in Canadian neonatal intensive care units. J Matern Fetal Neonatal Med 31(21): 2862-2869.

11. Dargaville PA, Gerber A, Johansson S, De Paoli AG, Kamlin COF, et al. (2016) Incidence and outcome of CPAP failure in preterm infants. Pediatrics American Academy of Pediatrics 138(1): e20153985.

12. Ammari A, Suri M, Milisavljevic V, Sahni R, Bateman D, et al. (2005) Variables associated with the early failure of nasal CPAP in very low birth weight infants. J Pediatr Elsevier 147(3): 341-347.

13. Tagliaferro T, Bateman D, Ruzal Shapiro C, Polin R (2015) Early radiologic evidence of severe respiratory distress syndrome as a predictor of nasal continuous positive airway pressure failure in extremely low birth weight newborns. J Perinatol 35: 99-103.

14. Kribs A, Roll C, Göpel W, Wieg C, Groneck P, et al. (2015) Nonintubated surfactant application vs conventional Therapy in extremely preterm infants: a randomized clinical trial. JAMA Pediatr 169(8): 723-730.

15. Dargaville PA, Sanoj KM, Jackson HD, Williams C, De Paoli A (2014) Impact of minimally invasive surfactant Therapy in infants 29-32 weeks gestation. Neonatology 113: 7-14.
16. Papile LA, Burstein J, Burstein R (1978) Incidence and evolution of subependymal and intraventricular hemorrhage: a study of infants with birth weight less than 1,500 grams. J Pediatr 92: 529-534.

17. Bell MJ, Ternberg JL, Feigin RD (1978) Neonatal necrotizing enterocolitis. Therapeutic decisions based upon clinical staging. Ann Surg 187: 1-7.

18. Chawla S, Natarajan G, Shankaran S (2017) Markers of successful Extubation in extremely preterm infants, and morbidity after failed Extubation. J Pediatr 189: 113-119.

19. Stoll BJ, Hansen NI, Bell EF (2015) Trends in care practices, morbidity, and mortality of extremely preterm neonates, 1993-2012. JAMA 314: 1039-1051.

20. Bixler GM, Powers GC, Clark RH (2017) Changes in the diagnosis and Management of Patent Ductus Arteriosus from 2006 to 2015 in United States neonatal intensive care units. J Pediatr 189: 105-112.

21. Aguar M, Vento M, Dargaville P (2014) Minimally Invasive Surfactant Therapy. Neo Reviews 15(7): e275-285.

22. Kanmaz HG, Erdeve O, Canpolat FE, Mutlu B, Dilmen U (2013) Surfactant administration via thin catheter during spontaneous breathing: randomized controlled trial. Pediatrics 131: e502-e509.

23. Bao Y, Zhang G Wu M, ma L, Zhu J (2015) a pilot study of less invasive surfactant administration in very preterm infants in a Chinese tertiary center. BMC Pediatr 15: 21.

24. Isayama T, Iwami H, Mc Donald S, Beyene J (2016) Association of Noninvasive Ventilation Strategies with mortality and bronchopulmonary dysplasia among preterm infants. JAMA 316: 611-624.

25. Roberts K, Brown R, Lampland A (2018) Laryngeal mask airway for surfactant Administration in Neonates: a randomized, controlled trial. J Pediatr 193: 40-46.

26. Finer NN, Merritt TA, Bernstein G (2015) An open label, pilot study of Aerosurf ${ }^{\circledR}$ combined with nCPAP to prevent RDS in preterm neonates. J Aerosol Med Pulm Drug Deliv 23: 303-309.

27. Minocchieri S, Berry CA, Pillow JJ Nebulised surfactant to reduce severity of respiratory distress: a blinded, parallel, randomized, controlled trial. Arch Dis Child Fetal Neonatal Ed Epub ahead of print.

28. Schmidt B, Roberts RS, Davis P (2006) Caffeine therapy for apnea of prematurity. N Engl J Med. 354(20): 2112-2121.

29. Patel RM, Zimmerman K, Carlton DP, Clark R, Benjamin DK, et al. (2017) Early caffeine prophylaxis and risk of failure of initial continuous positive airway pressure in very low birth weight infants. J Pediatr 109: 108-111.

30. Katheria AC, Sauberan JB, Akotia D, Rich W, Durham J, et al. (2015) A pilot randomized controlled trial of early versus routine caffeine in extremely premature infants. Am J Perinatol 32: 879-886.

31. Beltempo M, Isayama T, Vento M, Lui K, Kusuda S, et al. (2009) Respiratory Management of Extremely Preterm Infants: an international survey. Neonatology 114: 28-36. 
ISSN: 2574-1241

DOI: 10.26717/BJSTR.2020.27.004450

Huỳnh Quang Huy. Biomed J Sci \& Tech Res

(c) (P) This work is licensed under Creative

Submission Link: https://biomedres.us/submit-manuscript.php

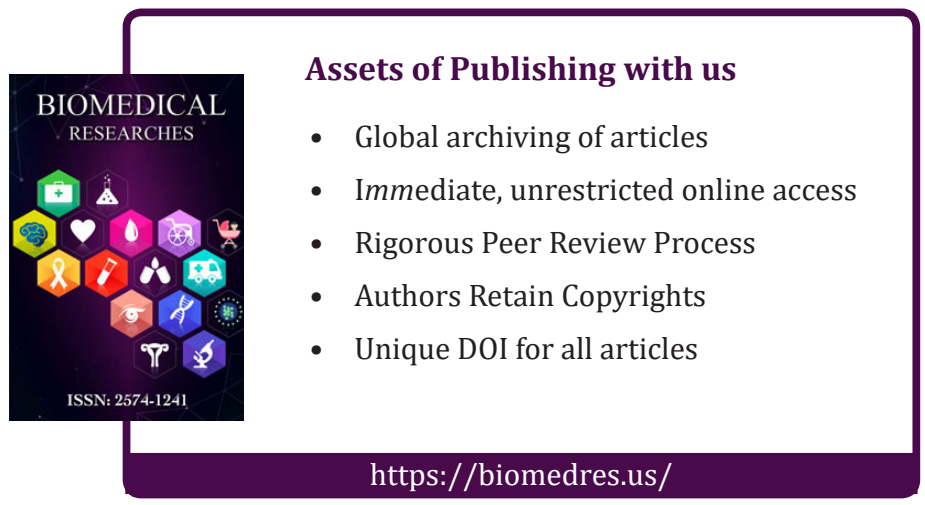

